doi: $10.15407 /$ ujpe62.08.0692

P.V. MEL'NYK, M.G. NAKHODKIN, M.I. FEDORCHENKO

Taras Shevchenko National University of Kyiv

(64/13, Volodymyrs'ka Str., Kyiv 01601, Ukraine)

\title{
INFLUENCE OF CHANGES IN DEFECT STATES PACS 73.20.At,73.30.+y ON THE PROPERTIES OF Si-Gd-O PHOTOCATHODE
}

\section{Introduction}

Photoelectron emitters with negative electron affinity, which are fabricated by activating the semiconductor surface with cesium and oxygen, found a wide practical application $[1,2]$. However, various groups of researchers continue to study them till now - in particular, on Si [3], GaAs [4,5], and diamond [6] in order to improve the physical models of their functioning and due to the necessity to change the activating Cs-O layers, which turned out insufficiently stable at the long-term usage [7]. The search for more stable compounds showed that it can be both oxides [8-10] and monosulfides [11-13] of rare-earth metal atoms.

In our previous works [14-17], we selected gadolinium and its oxides for researches, since they have higher binding energies in comparison with $\mathrm{Cs}-\mathrm{O}$. They are more stable and survive the annealing at high temperatures $\left(600-900{ }^{\circ} \mathrm{C}\right)$. Ferromagnetic gadolinium also gives hope for the creation of spinpolarized emission sources on its basis [18]. While studying the coadsorption of $\mathrm{Gd}$ and $\mathrm{O}$ atoms on the $\mathrm{Si}(113)$ and $\mathrm{Si}(100)$ surfaces [14-17], we established that those surfaces can be used for the creation of a photocathode with a low work function $\varphi \approx 1 \mathrm{eV}$ and negative electron affinity. The low work function

(C) P.V. MEL'NYK, M.G. NAKHODKIN, M.I. FEDORCHENKO, 2017

692 is connected with a complicated structure of dipoles on the cathode surface. However, both our and analogous researches of other authors $[8,16]$ have not ultimately established yet the origin of oxidation products. It is not known exactly whether the oxidation product consists of a mixture of $\mathrm{Si}$ and $\mathrm{Gd}$ oxides (or their nanoclusters) or a ternary compound of the $\mathrm{Gd}_{2} \mathrm{Si}_{2} \mathrm{O}_{7}$ silicate type. In the simplest case of $\mathrm{O}-$ $\mathrm{Gd}$ dipoles, the low work function is associated with the displacement of electrons from electropositive Gd atoms located on the surface toward electronegative $\mathrm{O}$ atoms located under them.

For the $\mathrm{Si}-\mathrm{Gd}-\mathrm{O}$ photocathode, we proposed a hypothetical variant of energy diagram (Fig. 1) [17]. It includes a thin layer of gadolinium oxide - probably $\mathrm{Gd}_{2} \mathrm{O}_{3}$ - located on a silicon substrate. The energy gap width in $\mathrm{Gd}_{2} \mathrm{O}_{3}$ amounts to $E_{g} \approx 5.3 \mathrm{eV}$ [19]. We supposed that the distance from the Fermi level $E_{\mathrm{F}}$ to the conduction band bottom in the $\mathrm{Gd}_{2} \mathrm{O}_{3}$ bulk is equal to about $2.7 \mathrm{eV}$. Structural defects in $\mathrm{Gd}_{2} \mathrm{O}_{3}$ give rise to the appearance of localized electron states in the energy gap below $E_{\mathrm{F}}$. Photons with the energy $h \nu$ in the interval $E_{g}>h \nu>E_{g} / 2$ can excite photoelectrons to the conduction band only from the levels located in the forbidden gap between the Fermi level and the valence band top. Those electrons can transit from the conduction band into the surface states located above the vacuum level and afterward can escape into vacuum through the surface barrier. The

ISSN 2071-0194. Ukr. J. Phys. 2017. Vol. 62, No. 8 
barrier structure can be similar to the dipole model of a barrier that was used in works $[1,2,4]$ for studying the photoelectron emission of $\operatorname{GaAs}(\mathrm{Cs}, \mathrm{O})$ cathodes, although the barrier shape and properties of our cathode still require additional research. At $h \nu>E_{g}$, photoelectrons can be excited into the conduction band from both the states located between the valence band top and $E_{\mathrm{F}}$, and from the valence band of $\mathrm{Gd}_{2} \mathrm{O}_{3}$.

In our previous works, we showed that the states of the surface and the near-surface layer of a cathode substantially affect its properties. For example, the adsorption of Gd atoms, low doses of oxygen atoms, and photocathode heating change the photocathode work function, as well as the form and intensity of photoelectron spectra (PESs), especially at energies of exciting quanta $E_{g}>h \nu>E_{g} / 2(h \nu=2.8$ and $3.1 \mathrm{eV}$ ) [17]. Those changes may probably be associated with a variation in the number of structural defects and the corresponding localized bulk and surface states. However, we have no enough evidence to justify the valiity of this hypothesis.

Therefore, in order to verify the proposed energy diagram and to search for methods to control the properties of a $\mathrm{Si}-\mathrm{Gd}-\mathrm{O}$ photocathode, the additional researches are carried out in what follows. They will concern the influence of the adsorption of gadolinium, oxygen, and hydrogen atoms on a photocathode (those atoms mainly interact with the photocathode surface) and the bombardment of a photocathode with Ar ions (they interact with deeper layers of a photocathode).

\section{Experimental Technique}

Researches were carried out in ultrahigh vacuum (about $10^{-10}$ Torr) with the use of photoelectron and Auger electron spectroscopies. The vacuum chamber contained (1) a gun for bombarding the specimen surface with Ar ions; (2) devices for the controllable deposition of Gd layers to a required coverage degree $\Theta_{\mathrm{Gd}}$; and (3) a system for treating the specimens with atomic oxygen or hydrogen to the given exposure $\xi$, which was measured in Langmuir units $\left(1 \mathrm{~L}=10^{-6}\right.$ Torr $\left.\mathrm{s}\right)$. Oxygen and hydrogen were let into the chamber from gas tanks by means of special controlling devices. Oxygen and hydrogen atoms were produced by dissociating the corresponding molecules at a white-hot tungsten wire.

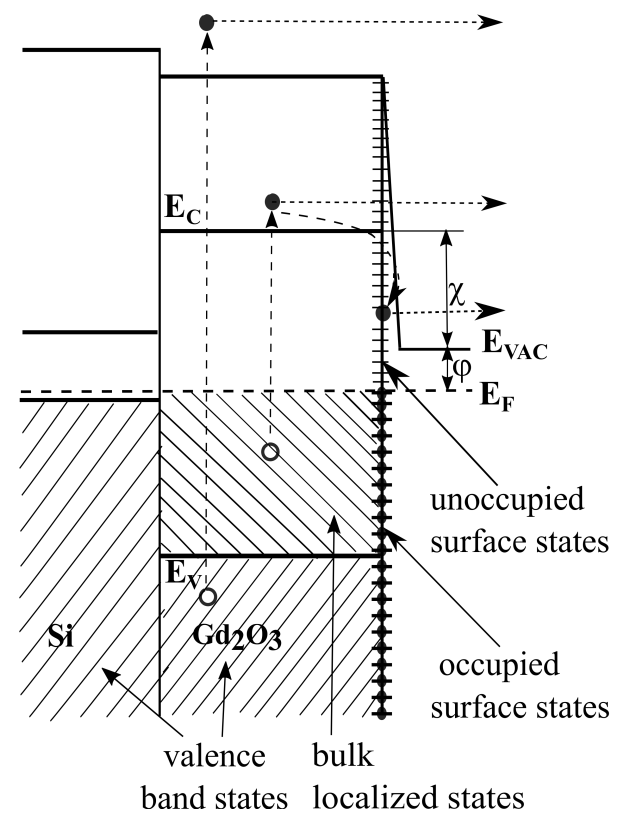

Fig. 1. Energy structure of the $\mathrm{Si}-\mathrm{Gd}_{2} \mathrm{O}_{3}$ system

PESs were excited by photons with energies $h \nu$ in an interval from 2.3 to $10.2 \mathrm{eV}$. Two types of light sources were used: (i) laser diodes with the quantum energies $h \nu \approx 2.3 \mathrm{eV}\left(h \nu<E_{g} / 2\right)$ and $h \nu \approx 3.1 \mathrm{eV}\left(E_{g}>h \nu>E_{g} / 2\right)$, which are close to the threshold energy of the photocathode excitation; and (ii) sources with $h \nu>E_{g}(h \nu=7.7$ and $10.2 \mathrm{eV}$ ), which were obtained with the help of the discharge in hydrogen and with the use of a vacuum ultraviolet monochromator. The intensity of a quantum flux produced by laser sources was estimated to be within the limits of about $10^{16}-10^{17}$ quantum/s, and that of monochromated hydrogen lines as about $10^{10}$ quantum/s [17]. The intensity of a laser source with $h \nu \approx 3.1 \mathrm{eV}$ was sufficient for the registration of the photoeffect near the cathode photoemission threshold, but insufficient for producing the irreversible changes in the cathode properties [17]. The PESs were measured with the help of a spherical analyzer of the retarding type with a stable work function of a collector. The specific features of PES measurements and work-function determination were described in works $[16,17]$ in more details.

As initial specimens for researches, we used photocathodes with the work function close to $1 \mathrm{eV}$. They were fabricated by the multicycle deposition of $\mathrm{Gd}$ atoms on the $\mathrm{Si}(100)$ surface, atomic oxygen adsorp- 


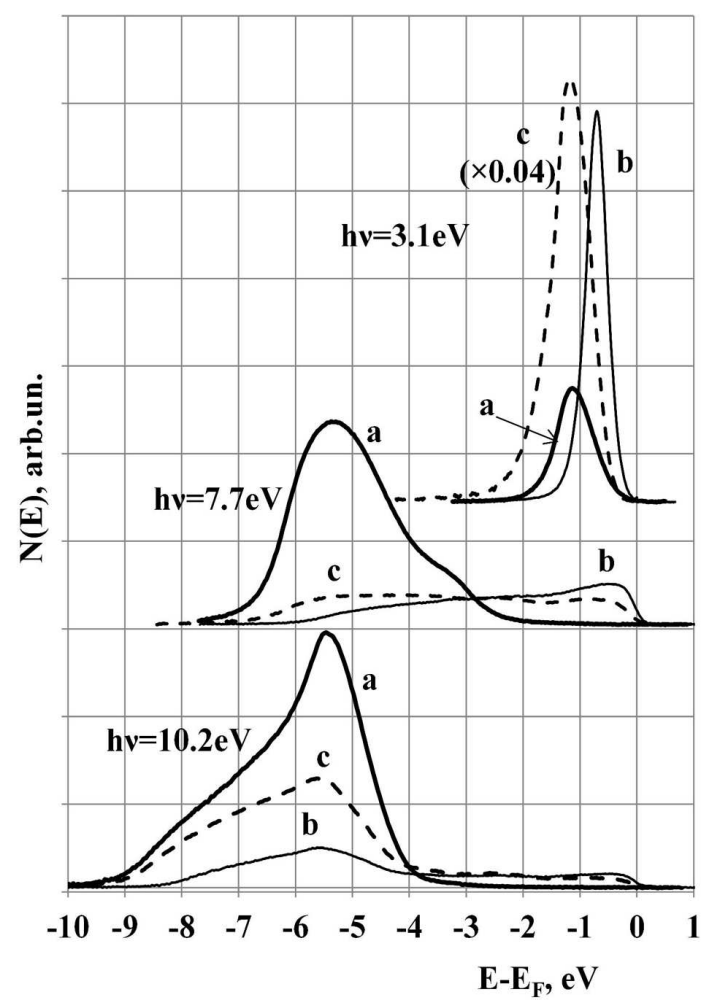

Fig. 2. PESs of the $\mathrm{Si}-\mathrm{Gd}-\mathrm{O}$ surface for $h \nu=10.2,7.7$, and $3.1 \mathrm{eV}$ : initial annealed $\mathrm{Si}-\mathrm{Gd}-\mathrm{O}$ specimen $(a)$, after the deposition of $1 \mathrm{ML}$ of $\mathrm{Gd}(b)$, after the exposition in atomic oxygen to about $10 \mathrm{~L}(c)$

tion, and annealing at $T \approx 600{ }^{\circ} \mathrm{C}[16]$. The $\mathrm{Si}(100)$ specimens were cut out from boron-doped wafers $(\rho \approx 0.02 \Omega \mathrm{cm})$. The obtained photocathodes turned out rather stable. They kept their properties after a lot of test cycles. If needed, they could be restored by annealing the specimens at $600{ }^{\circ} \mathrm{C}$. The thickness of a $\mathrm{Gd}_{2} \mathrm{O}_{3}$ layer formed on the photocathode surface was evaluated to equal about $15 \mathrm{~nm}$. No effects induced by the electric charge accumulation in the oxidized Gd layer were observed.

\section{Results of Researches and Their Discussion}

Depending on how we affected the properties of the initial photocathode, our researches can be divided into two groups. In the first group, the cathode properties changed under the influence of additionally deposited monolayers of $\mathrm{Gd}$ atoms and the adsorption of oxygen atoms. In the second group, they changed under the influence of 800-eV Ar ions and the adsorption of hydrogen atoms.

In Fig. 2, typical PESs of the initial photocathode are depicted. They were excited by photons with the energies $h \nu=10.2,7.7$, and $3.1 \mathrm{eV}$, respectively. According to the energy diagram (Fig. 1), the quantum energies $h \nu=10.2$ and $7.7 \mathrm{eV}$ are enough for the excitation of photoelectrons from the energy states both in the forbidden gap and in the valence band of the oxidized Gd layer. At $h \nu=10.2$ and $7.7 \mathrm{eV}$, a wide intensive maximum at a binding energy of about $5.5 \mathrm{eV}$ is well-distinguished first of all. It is related to the excitation of photoelectrons from $\mathrm{O} 2 \mathrm{p}$ states in the valence band of gadolinium oxide [810,16]. The PES intensity is insignificant in a binding energy interval of $0-3 \mathrm{eV}$ for $h \nu=10.2 \mathrm{eV}$, and in an interval of $0-2 \mathrm{eV}$ for $h \nu=7.7 \mathrm{eV}$. This is a result of a considerably lower density of states in the energy gap of $\mathrm{Gd}_{2} \mathrm{O}_{3}$ in comparison with that in its valence band.

Quanta with the lower energy $h \nu=3.1 \mathrm{eV}$, i.e. when $E_{g}>h \nu>E_{g} / 2$, excite PESs with an absolutely different shape. Near $E_{\mathrm{F}}$, one can see a maximum that looks like a Gaussian with a halfwidth of about $0.8 \mathrm{eV}$. In this case, photoelectrons are excited from the filled defect states located in the energy gap near $E_{\mathrm{F}}$. The absence of PES maximum in a vicinity of $E_{\mathrm{F}}$ at $h \nu=10.2$ and $7.7 \mathrm{eV}$ stems from a considerably lower flux intensity of those quanta in comparison with the flux intensity of quanta from the source with $h \nu=3.1 \mathrm{eV}$. At $h \nu \approx 2.3 \mathrm{eV}\left(h \nu<E_{g} / 2\right)$, the photoeffect was not registered at any work function value.

The deposition of a Gd monolayer (ML) on the surface of the initial specimen changes the PES shape (Fig. 2, curves $b$ ). First, the low-energy PES edge shifts toward $E_{\mathrm{F}}$, which means that the work function grows from about $1 \mathrm{eV}$ to about $1.7 \mathrm{eV}$. Second, the PES intensity near $E_{\mathrm{F}}$ considerably increases at $h \nu=10.2$ and $7.7 \mathrm{eV}$, and the maximum associated with photoelectrons excited from the O2p states of gadolinium oxide decreases. The growth of the PES intensity near $E_{\mathrm{F}}$ is an attribute of the surface metallization ( $5 d 6 s$ electrons of $\mathrm{Gd}$ ) [8], whereas a reduction of the maximum associated with $\mathrm{O} 2 \mathrm{p}$ electrons is a result of both the screening of oxygen atoms by additionally deposited Gd atoms and the growth of the work function value. The latter is a result of the appearance of nonoxidized Gd atoms on the sur- 
face. Despite that the work function increased after the deposition of an additional layer of Gd atoms, the intensity of PES at $h \nu=3.1 \mathrm{eV}$ became approximately twice as large. Since $E_{g}>h \nu>E_{g} / 2$, so that photoelectrons are excited from the forbidden gap in this case, the drastic growth of the photoemission can be associated with a substantial growth of the structural defect concentration in the cathode and the corresponding growth of localized states in the $\mathrm{Gd}_{2} \mathrm{O}_{3}$ energy gap.

In Fig. 3, the Auger-electron spectra (AESs) of the initial Si-Gd-O photocathode (curve $a$ ) and after its modification by depositing $1 \mathrm{ML}$ of Gd or treating with $\mathrm{Ar}$ ions (curves $b$ and $c$, respectively) are exhibited. The AES of the initial cathode distinctly demonstrates the following lines: (1) lines of oxidized gadolinium $\operatorname{Gd}\left(N_{4,5} N_{6,7} O_{2,3}\right), \operatorname{Gd}\left(N_{3} N_{4,5} N_{6,7}\right)$, and $\operatorname{Gd}\left(N_{4,5} N_{6,7} N_{6,7}\right)$ at $E=110,128$, and $140 \mathrm{eV}$, respectively [20]; (2) lines of partially oxidized $\mathrm{Si}$ $\left(\mathrm{SiO}_{x}\right)$ at $E=68$ and $86 \mathrm{eV}$ [21]; and (3) a hardly distinguishable LVV line of pure Si at $E=92 \mathrm{eV}$. The origin of the Auger line at $86 \mathrm{eV}$ can be rather complicated, because the Auger line $\operatorname{Gd}\left(N_{1} N_{4,5} N_{4,5}\right)$ can also be observed at this energy [20]. The additional monolayer of Gd atoms results in an increase in the LVV line intensity for pure Si (curve $b$ in Fig. 3), which points to an increase in the concentration of nonoxidized $\mathrm{Si}$ in the cathode. Furthermore, the intensity of the Auger line $\operatorname{Gd}\left(N_{3} N_{4,5} N_{6,7}\right)$ at $128 \mathrm{eV}$ decreases, which is a result of the superposition of contributions from the phases of oxidized and nonoxidized Gd [16] in the near-surface layer; the thickness of the latter equals to the escape depth of those Auger electrons. The appearance of the Si LVV line in the AESs of the cathode after the deposition of additional Gd atoms allows us to consider it as resulting from the formation of structural defects in the near-surface region of the cathode.

Figure 2 (curves $c$ ) exhibits the PESs for $h \nu>E_{g}$ $(h \nu=10.2$ and $7.7 \mathrm{eV})$ modified after the cathode with the additional $1 \mathrm{ML}$ of Gd was exposed to atomic oxygen $(10 \mathrm{~L})$. After the exposition, the energy widths of PES increased, which means a reduction of the work function value, and the maximum intensities of photoelectrons excited from the O2p states of gadolinium oxide also increased. We assume that a reduction of the work function is a result of the partial oxidation of added Gd atoms and the corresponding increase of the $\mathrm{O}-\mathrm{Gd}$ dipole con-

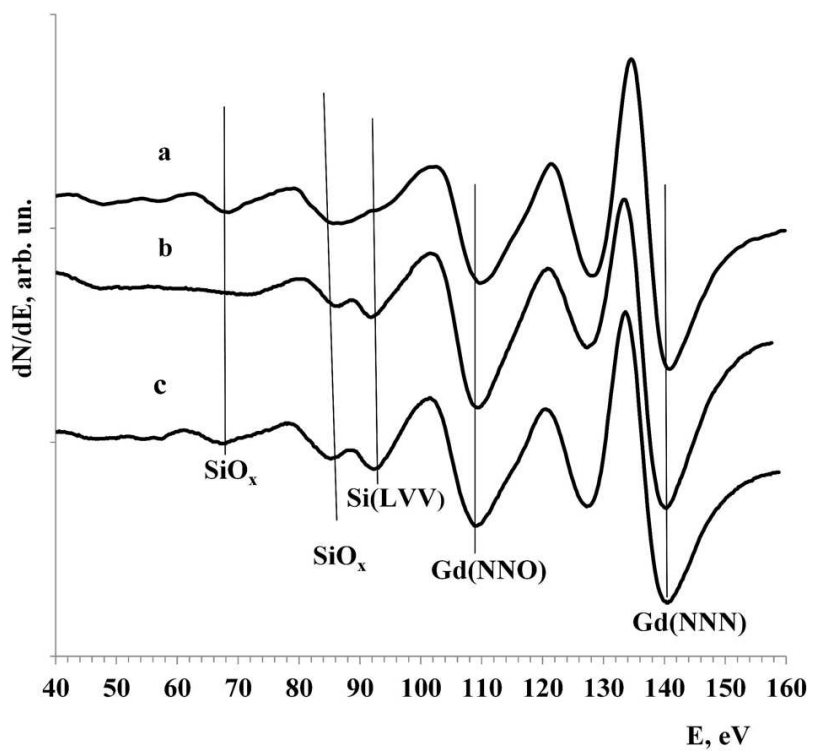

Fig. 3. AESs of the $\mathrm{Si}-\mathrm{Gd}-\mathrm{O}$ system: the initial surface $(a)$, after the deposition of $1 \mathrm{ML}$ of $\mathrm{Gd}(b)$, after the bombardment of the initial surface with Ar ions (c)

centration. A decrease of the work function was accompanied by a substantial (by almost two orders of magnitude) increase in the intensity of the PESs excited near the photoeffect threshold by photons with $h \nu=3.1 \mathrm{eV}$. In this case, the excited photoelectrons had low energies, so that a decrease of the work function at the oxygen adsorption considerably increased the probability of their emission into vacuum. It is possible that the oxygen adsorption somewhat diminished the density of the localized bulk states located in the forbidden gap of $\mathrm{Gd}_{2} \mathrm{O}_{3}$ near $E_{\mathrm{F}}$, but the reduction of the work function had a much stronger effect on the PES intensity.

An example of changes in PESs at $h \nu=7.7$ and $3.1 \mathrm{eV}$, which occur after the bombardment of the initial cathode surface with $800-\mathrm{eV}$ Ar ions to a dose of $5 \times 10^{14} \mathrm{~cm}^{-2}$, is shown in Fig. 4 . For this experiment, a specimen with a slightly narrower layer of oxidized Gd was used in comparison with the specimen with an additionally deposited Gd layer. The AEss of both specimens turned out identical (Fig. 3, curve $a$ ), whereas their PESs at $h \nu=7.7 \mathrm{eV}$ had different intensities of the peculiarity at a binding energy of about $3.3 \mathrm{eV}$ (Figs. 2 and 4). This fact is connected with a considerably larger escape depth of photoelectrons excited at $h \nu=7.7 \mathrm{eV}$ than Auger electrons with an energy of 100-140 eV [22]. The PES pecu- 


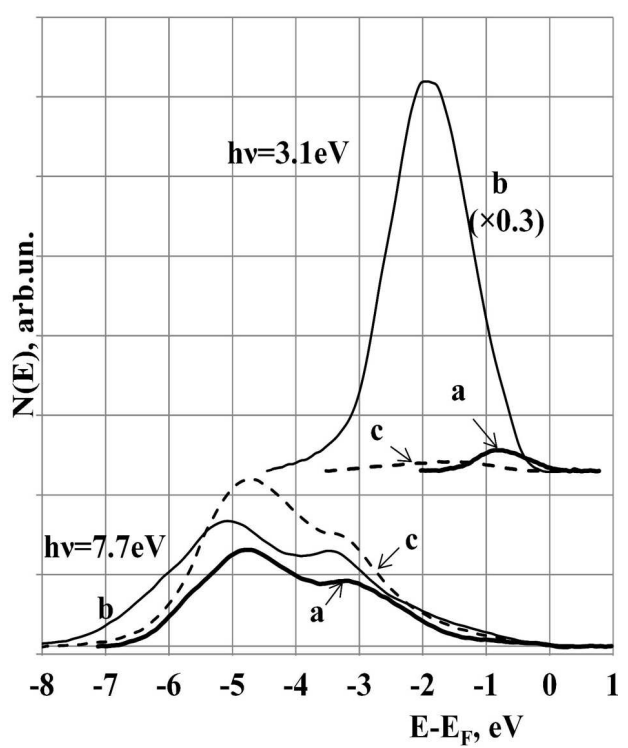

Fig. 4. PESs of the Si-Gd-O surface for $h \nu=7.7$ and $3.1 \mathrm{eV}$ : initial annealed $\mathrm{Si}-\mathrm{Gd}-\mathrm{O}$ specimen $(a)$, after its bombardment with Ar ions $(b)$, after the following exposition in atomic hydrogen to $50 \mathrm{~L}(c)$

liarity at a binding energy of about $3.2 \mathrm{eV}$ is induced by $\mathrm{Si}$ atoms from the transient layer located between the $\mathrm{Si}$ substrate and $\mathrm{Gd}_{2} \mathrm{O}_{3}$ [17].

From Fig. 4, one can see that, after the bombardment with Ar ions, the intensity of PES at $h \nu=$ $=7.7 \mathrm{eV}$ increased insignificantly and without substantial qualitative modifications of its shape. The characteristic maxima and the low-energy edge of the PES are shifted together away from $E_{\mathrm{F}}$ (curve $b$ ), which testifies to a reduction of the work function owing to the band bending downward. However, for $h \nu=3.1 \mathrm{eV}$, when $E_{g}>h \nu>E_{g} / 2$, the PES intensity increased by more than two orders of magnitude (Fig. 4, curve $b$ ), and its half-width became almost twice as large. The bombardment with Ar ions also gave rise to the appearance of a Si LVV line in the Auger spectrum (Fig. 3, curve $c$ ), which can be associated with the creation of additional structural defects in the cathode and the corresponding nonsaturated orbitals in its near-surface region.

The exposition of the Si-Gd-O surface modified by $\mathrm{Ar}$ ions to atomic hydrogen $(50 \mathrm{~L})$ resulted in a shift of the maxima and low-energy edge of PES for $h \nu=7.7 \mathrm{eV}$ toward $E_{\mathrm{F}}$ (Fig. 4, curve $c$ ), to their positions before the bombardment with Ar ions. This fact testifies to the elimination of the band bend- ing induced by Ar ions and an increase of the work function to a value characteristic of the initial specimen. The exposition of the specimen in atomic hydrogen considerably diminished the intensity of PES for $h \nu=3.1 \mathrm{eV}$ (Fig. 4, curve $c$ ). Hydrogen saturates dangling bonds and thus reduces the concentration of filled electron states in the energy gap. Similar results were obtained in work [23], when studying the bombardment of the diamond surface with 1000-eV Ar ions to a dose of an order of $10^{14} \mathrm{~cm}^{-2}$. According to PES modifications, argon ions create charged defect states and the band bending downward in the nearsurface region of the diamond electrode. The properties of the surface could be easily restored by its annealing or hydrogenating.

The obtained results of researches correspond to our energy diagram of the electron structure in the cathode. The PESs for $h \nu=10.2$ and $7.7 \mathrm{eV}$ depicted in Fig. 2 (curves $a$ ) reflect the convolution of the contributions from occupied states in the oxidized $\mathrm{Gd}$ phase $\left(\mathrm{Gd}_{2} \mathrm{O}_{3}\right)$ in the initial photocathode, which are located in the valence and forbidden bands, as well as the free states located in the conduction band of $\mathrm{Gd}_{2} \mathrm{O}_{3}$. The PES at $h \nu=3.1 \mathrm{eV}$ (Fig. 2, curve $a$ ) informs about localized electron states that are located in the forbidden gap of oxidized Gd and free states in the oxidized Gd located above the vacuum level.

The localized electron states in the energy gap of $\mathrm{Gd}_{2} \mathrm{O}_{3}$ arise due to structural defects in the cathode. After the deposition of an additional coverage (Gd atoms) onto the initial photocathode surface, the number of defects in its near-surface region considerably increases. As a result, the density of localized electron states in the forbidden gap of $\mathrm{Gd}_{2} \mathrm{O}_{3}$ and the intensities of PESs at $h \nu=3.1 \mathrm{eV}\left(E_{g}>h \nu>E_{g} / 2\right)$ substantially increase. The hyperactivity of Gd atoms and the resulting diffusion of $\mathrm{Si}$ atoms from the silicon substrate to Gd islands along grain boundariesthose two phenomena can be an important origin of a growth of the structural defect concentration. The deposition of chemically active Gd atoms onto the cathode surface induces an exothermic reaction between Gd and the oxidized Si phase. This process can also give rise to the formation of additional structural defects. As a result of this reaction, additional phases of Si oxide and silicide, i.e. new structural defects in the $\mathrm{Gd}_{2} \mathrm{O}_{3}$ matrix, can emerge $[9,26]$.

After the deposition of $1 \mathrm{ML}$ of $\mathrm{Gd}$, the PESs at $h \nu=10.2$ and $7.7 \mathrm{eV}$ (Fig. 2, curves $b$ ) are a su- 
perposition of corresponding PESs for the phases of oxidized Gd, nonoxidized Gd, and Gd silicide, each of which contains the information about occupied electron states in those phases. The PES at $h \nu=3.1 \mathrm{eV}$ (Fig. 2, curve $b$ ) contains no information about the $5 d 6 s$ states in the pure Gd phase, because photoelectrons excited from those states have low energies and cannot escape into vacuum owing to rather high work function of pure $\mathrm{Gd}(3.1 \mathrm{eV})$ [27]. The exposition in oxygen reduces the contributions of pure $\mathrm{Gd}$ and its silicide phases, which diminishes the work function for the cathode surface due to an increase of the relative amount of the oxidized Gd phase in the near-surface region.

Our calculations carried out with the use of the software code SRIM-2008 [28] showed that the ion range of $\mathrm{Ar}$ ions with an energy of $800 \mathrm{eV}$ along the normal to the $\mathrm{Gd}_{2} \mathrm{O}_{3}$ surface amounts to about $23 \AA$. This means that the radiation-induced structural defects are formed by Ar ions along their whole range in the specimen volume [29]. This circumstance allows the bombardment of the cathode with Ar ions to be considered as increasing the number of structural defects in the cathode volume and the corresponding number of localized bulk states. The growth in the number of structural defects due to the appearance of radiation-induced ones considerably increases the intensity of PES at $h \nu=3.1 \mathrm{eV}$, when $E_{g}>h \nu>E_{g} / 2$ (Fig. 4). The saturation of dangling bonds at structural defects by atomic hydrogen reduces the intensity of PES at $h \nu=3.1 \mathrm{eV}$ to values that are smaller than values typical of the initial photocathode. From whence, it follows that the bombardment of the $\mathrm{Si}-\mathrm{Gd}-\mathrm{O}$ cathode surface with Ar ions and its exposition to atomic hydrogen can be used to control the spectral properties of this cathode.

From our researches, it follows that the properties of the $\mathrm{Si}-\mathrm{Gd}-\mathrm{O}$ cathode substantially depend on the concentration of electron states that are induced by structural defects. The origin of structural defects in the cathode that are formed under the action of monoatomic layers of gadolinium atoms and argon ions still requires additional studies. However, the fact that their concentration increases with the LVV Auger line intensity of nonoxidized Si testifies to an important role of structural defects induced by $\mathrm{Si}$ atoms. Therefore, it is not excluded that the cathode composition includes silicate $\mathrm{Gd}_{2} \mathrm{Si}_{2} \mathrm{O}_{7}$ or a mixture of $\mathrm{Gd}_{2} \mathrm{Si}_{2} \mathrm{O}_{7}, \mathrm{Gd}_{2} \mathrm{O}_{3}$, and $\mathrm{Gd}_{x} \mathrm{Si}_{y}[8,9]$. This assump- tion requires further researches within more perfect methods for studying the structure and composition of the cathode and its surface.

\section{Conclusions}

Modifications in properties of the $\mathrm{Si}-\mathrm{Gd}-\mathrm{O}$ photo-

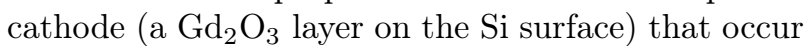
under the influence of additional monoatomic Gd layers and Ar ions have been studied. It is found that, after the deposition of an additional coverage of $\mathrm{Gd}$ atoms onto the initial photocathode surface, as well as after its bombardment with Ar ions, the number of defects in the near-surface region of the cathode considerably increases. As a result, the density of localized electron states in the forbidden gap of $\mathrm{Gd}_{2} \mathrm{O}_{3}$ and the intensities of PESs at $h \nu=3.1 \mathrm{eV}$ $\left(E_{g}>h \nu>E_{g} / 2\right)$ grow substantially. New defects can be induced by the dangling orbitals of Si atoms in the near-surface region of the cathode. It is confirmed that the energy diagram proposed for the photocathode can be used, while analyzing the cathode properties. From the viewpoint of the further improvement of such cathodes, researches of their structure, the role of silicon substrate, and the quantitative determination of emission parameters would be highly important. Nevertheless, the stability of the photocathode and the easiness of its restoration give us hope for that it can be applied after a further improvement.

1. R. L. Bell. Negative Electron Affinity Devices. (Clarendon, 1973).

2. N.A. Soboleva. A new class of electronic emitters. Usp. Fiz. Nauk 111, 331 (1973) (in Russian).

3. L.N. Dinh, W. McLean, M.A. Schildbach, M. Balooch. Synthesis and characterization of $\mathrm{Si} / \mathrm{Cs} / \mathrm{O}$ nanocluster thin films with negative electron affinity. Phys. Rev. B 59, 15513 (1999).

4. C.Y. Su, W.E. Spicer, I. Lindau. Photoelectron spectroscopic determination of the structure of $(\mathrm{Cs}, \mathrm{O})$ activated GaAs (110) surfaces. J. Appl. Phys. 54, 1413 (1983).

5. Lihui Guo, Hou Xun. Analysis of photoelectron emission of transmission-mode NEA GaAs photocathodes. J. Phys. D 22, 348 (1989).

6. L. Diederich, O.M. Kuttel, P. Aebi, L. Schlapbach. Electron affinity and work function of differently oriented and doped diamond surfaces determined by photoelectron spectroscopy. Surf. Sci. 418, 219 (1998).

7. Zhang Jun-Ju, Chang Ben-Kang, Fu Xiao-Qian, Du YuJie, Li Biao et al. Influence of cesium on the stability of GaAs photocatode. Chin. Phys. B 20, 087902 (2011). 
8. W.A. Henle, M.G. Ramsey, F.P. Netzer,R. Cimino, W. Braun et al. Reactions at the Gd-Si(111) $7 \times 7$ interface: Promotion of Si oxidation. Phys. Rev. B 42, 11073 (1990).

9. R. Hofmann, W.A. Henle, H. Ofner, M.G. Ramsey, F.P. Netzer et al. Physical and chemical effects at rareearth-metal $\mathrm{SiO}_{2}-\mathrm{Si}$ structures. Phys. Rev. B 47, 10407 (1993).

10. K. Wandelt, C.R. Brundle. The interaction of oxygen with gadolinium: UPS and XPS studies. Surf. Sci. 157, 162 (1985).

11. R.I.R. Blyth, C. Searle, N. Tucker, R.G. White, T.K. Johal et al. Molecular adsorption on the (0001) surfaces of rareearth metals. Phys. Rev. B 68, 205404 (2003).

12. M. Cahay, P. Boolchand, S.B. Fairchild, L. Grazulis, P.T. Murray et. al. Review Article: Rare-earth monosulfides as durable and efficient cold cathodes. J. Vac. Sci. Technol. B 29 (6), 06F602 (2011).

13. O. Erikson, M. Cahay, J.M. Wills. Negative electron affinity material: LaS on InP. Phys. Rev. B 65, 033304 (2001).

14. M.G. Nakhodkin, M.I. Fedorchenko. Formation of Gd/Si(113) interface. Visn. Kyiv Univ. Ser. Fiz.-Mat. Nauky No. 4, 261 (2012) (in Ukrainian).

15. M.G. Nakhodkin, M.I. Fedorchenko. Interaction of Gd and O with $\mathrm{Si}(113)$ surface. Visn. Kyiv Univ. Ser. Fiz.-Mat. Nauky No. 1, 239 (2014) (in Ukrainian).

16. M.G. Nakhodkin, M.I. Fedorchenko. Interaction of oxygen and gadolinium with $\mathrm{Si}(100) 2 \times 1$. Formatiom of a system with a work function of $1 \mathrm{eV}$. Ukr. J. Phys. 60, 97 (2015).

17. M.G. Nakhodkin, M.I. Fedorchenko. Photoelectron emission of Si-Gd-O cathode. Ukr. J. Phys. 61, 248 (2016).

18. Byoung-Chul Min, K. Motohashi, C. Lodder, R. Jansen. Tunable spin-tunnel contacts to silicon using low-workfunction ferromagnets. Nature Mater. 5, 817 (2006).

19. C.R. Abernathy, B.P. Gila, A.H. Onstine, S.J. Pearton, Jihyun Kim Jour et al. Progress in novel oxides for gate dielectrics and surface passivation of GaN/AlGaN heterostructure field effect transistors. J. Semicond. Technol. Sci. 3, 13 (2003).

20. W. Farber, P. Braun. Oxygen exposure of Sm, Gd and Tb studied by Auger electron spectroscopy. Surf. Sci. 41, 195 (1974).

21. P. Morgen, J.H. Onsgaard, S. Tougaard. Observation of changes in the electronic density of states at a Si (111) surface during adsorption of oxygen by Auger electron spectroscopy. Appl. Phys. Lett. 34, 488 (1979).
22. T.A. Carlson. Photoelectron and Auger Spectroscopy (Plenum Press, 1975) [ISBN: 978-1-4757-0120-3].

23. J.S. Foord, C.H. Goeting. Diamond electrodes modified by argon ion bombardment. Phys. Status Solidi A 201, 2439 (2004).

24. R. Pretorius, J.M. Harris and M.A. Nicolet. Reaction of thin metal films with $\mathrm{SiO}_{2}$ substrates. Solid State Electron. 21, 667 (1978)

25. G. Molnar, G. Peto, E. Kotai, L. Guczi. The oxidation of $\mathrm{Gd}_{0.95} \mathrm{SiO}_{0.05}$ layers. Vacuum 41, 1640 (1990).

26. B.A. Orlowski, B.J. Kowalski, E. Guziewicz, E. Lusakowskaa, V. Osinniyet et al. Microscopic (AFM) and resonant photoemission study of $\mathrm{Gd} / \mathrm{Si}(111)$ interface. Radiat. Phys. Chem. 78, S22 (2009).

27. M.V. Nikolic, S.M. Radic, V. Minic, M.M. Ristic. The dependence of the work function of rare earth metals on their electron structure. Microelectron. J. 27, 93 (1996).

28. Interaction of Ions with Matter [http://www.srim.org].

29. R. Berish. Sputtering by Particle Bombardment (Springer, 1981).

Received 31.07.17.

Translated from Ukrainian by O.I. Voitenko

П.В. Мелъник, М.Г. Находкін, М.І. Федорченко

ВПЛИВ ЗМІН ДЕФЕКТНИХ СТАНІВ

НА ВЛАСТИВОСТІ ФОТОКАТОДА $\mathrm{Si}-\mathrm{Gd}-\mathrm{O}$

$\mathrm{P}$ е $з$ ю м е

Методами фотоелектронної ( $h \nu=2,3-10,2$ eВ) та ожеелектронної спектроскопій досліджено зміни електронних та емісійних властивостей фотокатода на основі багатошарової структури окислених атомів $\mathrm{Gd}$ (імовірно $\mathrm{Gd}_{2} \mathrm{O}_{3}$ ) на підкладці із $\mathrm{Si}(100)$ після напилення на його поверхню додаткових шарів атомів Gd та бомбардування іонами Ar. Встановлено, що зміни властивостей фотокатода залежать від дефектності його приповерхневого шару і зумовлені зміною концентрації локалізованих електронних станів, розташованих в забороненій зоні $\mathrm{Gd}_{2} \mathrm{O}_{3}$. Показано, що бомбардування іонами Ar та експозиція в атомарному водні катода $\mathrm{Si}-\mathrm{Gd}-$ О може використовуватись для керування його спектральними та емісійними характеристиками. Підтверджена можливість використання запропонованої нами енергетичної схеми фотокатода для якісного аналізу його властивостей. 